\title{
Erratum zu: Längenkonzepte von Kindern im Elementarbereich
}

\section{Erratum zu:}

\section{J. Zöllner, Längenkonzepte von Kindern im Elementarbereich, https://doi.org/10.1007/978-3-658-27671-3}

Die Originalversion dieses Buches wurde verlagsseitig versehentlich ohne die Abbildungen auf den Seiten 107 und 138 veröffentlicht. Diese Abbildungen wurden nun eingefügt und werden wie nachstehend dargestellt.

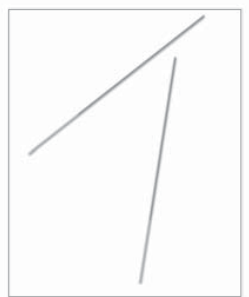

Abbildung 22: Ungefähre Position der Kreppbandstreifen auf dem Boden

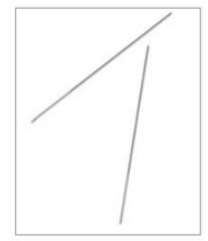

$\mathrm{n}=40$

Die korrigierten Versionen der Kapitel sind verfügbar unter https://doi.org/10.1007/978-3-658-27671-3_4 https://doi.org/10.1007/978-3-658-27671-3_5 